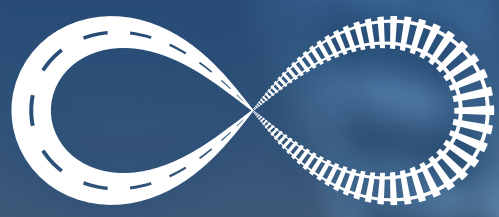

CETRA $^{2018}$

$5^{\text {th }}$ International Conference on Road and Rail Infrastructure 17-19 May 2018, Zadar, Croatia

Road and Rail Infrastructure V

Stjepan Lakušić - EDITOR

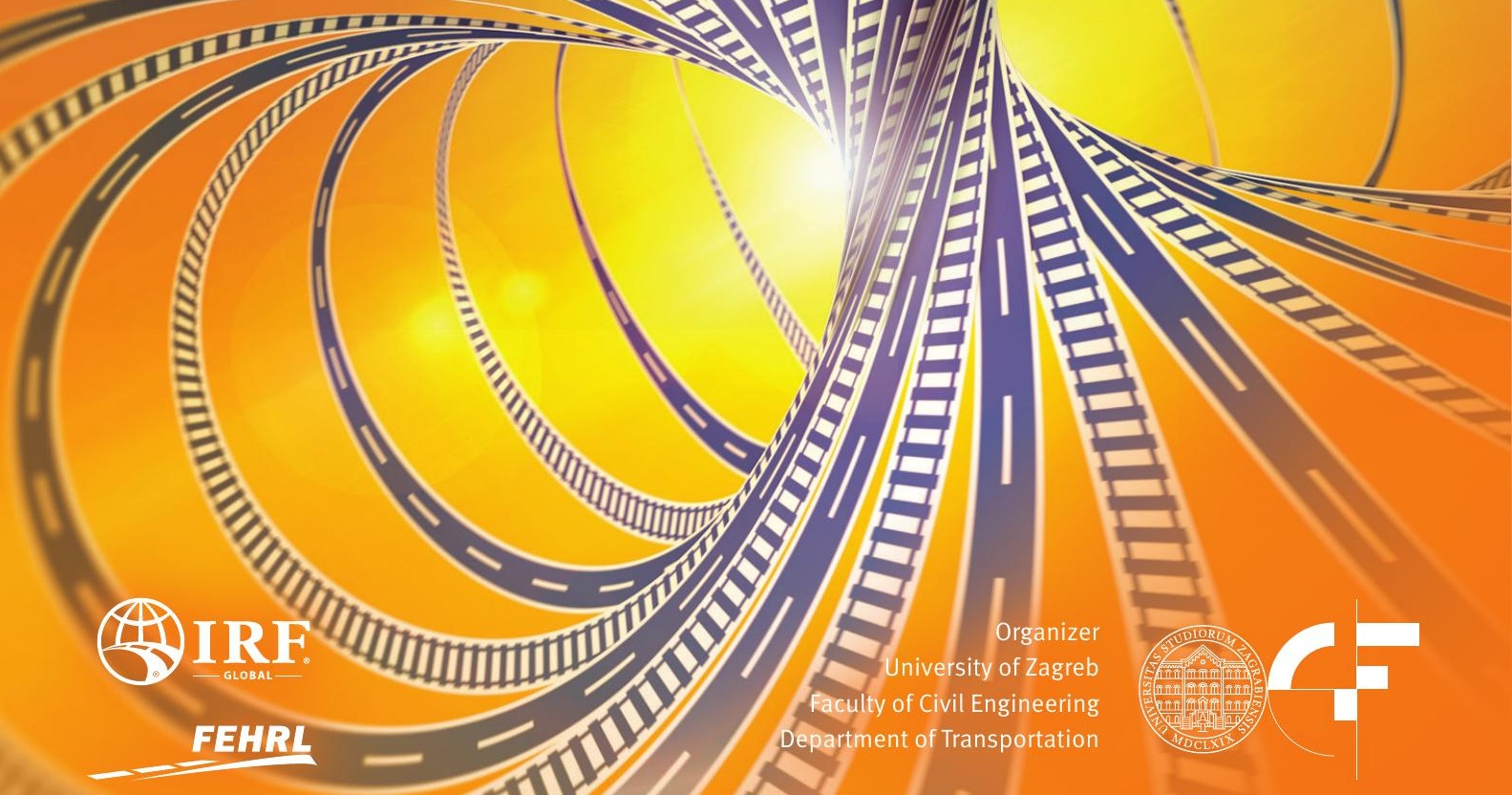




\section{CETRA $^{2018}$}

\section{$5^{\text {th }}$ International Conference on Road and Rail Infrastructure 17-19 May 2018, Zadar, Croatia}

TITLE

Road and Rail Infrastructure V, Proceedings of the Conference CETRA 2018

EDITED BY

Stjepan Lakušić

ISSN

$1848-9850$

ISBN

978-953-8168-25-3

DOI

10.5592/CO/CETRA.2018

PUBLISHED BY

Department of Transportation

Faculty of Civil Engineering

University of Zagreb

Kačićeva 26, 10000 Zagreb, Croatia

DESIGN, LAYOUT \& COVER PAGE

minimum d.o.o.

Marko Uremović · Matej Korlaet

PRINTED IN ZAGREB, CROATIA BY

“Tiskara Zelina”, May 2018

COPIES

500

Zagreb, May 2018.

Although all care was taken to ensure the integrity and quality of the publication and the information herein, no responsibility is assumed by the publisher, the editor and authors for any damages to property or persons as a result of operation or use of this publication or use the information's, instructions or ideas contained in the material herein.

The papers published in the Proceedings express the opinion of the authors, who also are responsible for their content. Reproduction or transmission of full papers is allowed only with written permission of the Publisher. Short parts may be reproduced only with proper quotation of the source. 
Proceedings of the

$5^{\text {th }}$ International Conference on Road and Rail Infrastructures - CETRA 2018

17-19 May 2018, Zadar, Croatia

\section{Road and Rail Infrastructure V}

\section{EDITOR}

Stjepan Lakušić

Department of Transportation

Faculty of Civil Engineering

University of Zagreb

Zagreb, Croatia 
CETRA $^{2018}$

$5^{\text {th }}$ International Conference on Road and Rail Infrastructure

17-19 May 2018, Zadar, Croatia

\section{ORGANISATION}

\section{CHAIRMEN}

Prof. Stjepan Lakušić, University of Zagreb, Faculty of Civil Engineering

Prof. emer. Željko Korlaet, University of Zagreb, Faculty of Civil Engineering

ORGANIZING COMMITTEE

Prof. Stjepan Lakušić

Prof. emer. Željko Korlaet

Prof. Vesna Dragčević

Prof. Tatjana Rukavina

Assist. Prof. Ivica Stančerić

Assist. Prof. Maja Ahac

Assist. Prof. Saša Ahac

Assist. Prof. Ivo Haladin

Assist. Prof. Josipa Domitrović

Tamara Džambas

Viktorija Grgić

Šime Bezina

Katarina Vranešić

Željko Stepan
Prof. Rudolf Eger

Prof. Kenneth Gavin

Prof. Janusz Madejski

Prof. Nencho Nenov

Prof. Andrei Petriaev

Prof. Otto Plašek

Assist. Prof. Andreas Schoebel

Prof. Adam Szeląg

Brendan Halleman

INTERNATIONAL ACADEMIC SCIENTIFIC COMMITTEE

Stjepan Lakušić, University of Zagreb, president

Borna Abramović, University of Zagreb

Maja Ahac, University of Zagreb

Saša Ahac, University of Zagreb

Darko Babić, University of Zagreb

Danijela Barić, University of Zagreb

Davor Brčić, University of Zagreb

Domagoj Damjanović, University of Zagreb

Sanja Dimter, J. J. Strossmayer University of Osijek

Aleksandra Deluka Tibljaš, University of Rijeka

Josipa Domitrović, University of Zagreb

Vesna Dragčević, University of Zagreb

Rudolf Eger, RheinMain Univ. of App. Sciences, Wiesbaden

Adelino Ferreira, University of Coimbra

Makoto Fujiu, Kanazawa University

Laszlo Gaspar, Széchenyi István University in Győr

Kenneth Gavin, Delft University of Technology

Nenad Gucunski, Rutgers University

Ivo Haladin, University of Zagreb

Staša Jovanović, University of Novi Sad

Lajos Kisgyörgy, Budapest Univ. of Tech. and Economics
Anastasia Konon, St. Petersburg State Transport Univ.

Željko Korlaet, University of Zagreb

Meho Saša Kovačević, University of Zagreb

Zoran Krakutovski, Ss. Cyril and Methodius Univ. in Skopje

Dirk Lauwers, Ghent University

Janusz Madejski, Silesian University of Technology

Goran Mladenović, University of Belgrade

Tomislav Josip Mlinarić, University of Zagreb

Nencho Nenov, University of Transport in Sofia

Mladen Nikšić, University of Zagreb

Andrei Petriaev, St. Petersburg State Transport University Otto Plašek, Brno University of Technology

Mauricio Pradena, University of Concepcion

Carmen Racanel, Tech. Univ. of Civil Eng. Bucharest

Tatjana Rukavina, University of Zagreb

Andreas Schoebel, Vienna University of Technology

Ivica Stančerić, University of Zagreb

Adam Szeląg, Warsaw University of Technology

Marjan Tušar, National Institute of Chemistry, Ljubljana

Audrius Vaitkus, Vilnius Gediminas Technical University

Andrei Zaitsev, Russian University of transport, Moscow 


\title{
FIELD PERFORMANCE EVALUATION OF UNBOUND GRANULAR MATERIALS USING THE FAST FALLING WEIGHT DEFLECTOMETER
}

\author{
Silvia Giuntoli, Chiara Pratelli, Giacomo Betti, Alessandro Marradi \\ University of Pisa, Civil and Industrial Engineering Department, Italy
}

\begin{abstract}
The use of innovative lightweight unbound granular aggregates for road and airfield constructions involves complex challenges related to their mechanical characterization and expected field performance. To analyze the materials resistance to repeated loads the common practice is to perform tests using a large triaxial testing machines. On the other side, as reported in the standards, the resulting ranking of the materials has to be confirmed by means of systems able to provide parameters closer to their real long-term behavior. On these premises a new procedure has been developed for the evaluation of field performance of an innovative recycled lightweight material, the so-called Glass-foam, used for airport embankment applications. The new approach arises from the specifications reported in UNI EN 13286-7 (Cyclic Load Triaxial Test for Unbound Mixtures) and involves the use of Fast Falling Weight Deflectometer (FFWD). This new device has been specifically designed to speed up the testing process (in comparison with the traditional Falling Weight Deflectometer-FWD) allowing the application of a great number of load drops over the same location in a reduced period of time and consequently it could be a feasible device for Accelerated Pavement Testing (APT). The procedure includes the dynamic application at different load levels to measure both the stiffness stress dependency and the relationship between the maximum stress condition and the development of permanent deformations in the material. In this paper are presented the APT field tests which have been performed at Fiumicino Airport (Italy) to validate glass-foam aggregates performance. The new approach has allowed to develop a specific performance criterion based on the accumulation of permanent deformations in the glass-foam layer.
\end{abstract}

Keywords: Accelerated Pavement Testing, Light Weight Aggregates, Glass foam, unbound materials, Fast Falling Weight Deflectometer

\section{Introduction}

The prediction of settlement values non-complying with the minimum levels of functionality is one on the major topic that must be considered for airport pavements construction. When this type of infrastructures is realized over a highly compressive soil different approaches can be considered to improve the bearing capacity of the entire structure and reduce the stresses induced by the traffic loads and the resulting settlements. Among these different methods the use of lightweight materials (such as Expanded Polystyrene EPS-blocks, expanded clay or the recently developed glass-foam aggregates) for embankment realization appears a promising possibility to reduce the vertical loads on weak subgrades and the settlement of the embankment weight without compromising the strength of the structure, also avoiding expensive structural solutions [1]. Granulated foamed glass (glass-foam) is produced by recycling wasted glass and generally consists of $8 \%$ by volume of glass and $92 \%$ of gas bobbles. The 
use of glass-foam as a lightweight material both for road and airfield embankments applications requires a specific characterization of its field performance $[2,3]$. The use of triaxial testing machine is generally considered the best option to analyse unbound materials resistance to repeated loads [4]. On the other side the resulting ranking of the materials need to be validated using systems able to provide parameters more representative of their real longterm behaviour [5]. In this paper are presented the results of a testing procedure performed to investigate the in situ performance and material field properties of glass foam aggregates for lightweight airport embankment construction, with regards to the specific case of Fiumicino (FCO) Airport in Italy [6].

\section{Objective and scope}

In this research an innovative procedure for the evaluation of field performance of glass-foam aggregates used for airport embankment construction is presented, involving the use of Fast Falling Weight Deflectometer (FFWD) as an Accelerated Pavement Tests (APT) device to study long term behaviour of the tested material [7]. The tests' main aim is to evaluate the amount of permanent deformations accumulated by the glass-foam layer as the number of load drops applied grows. A relation between the maximum vertical stress and the allowable number of load repetitions has been established. This approach allowed also to evaluate the glass-foam endurance limit, which is the vertical stress level below which failure never occurs, even for an indefinitely large number of loading cycles. This new approach is based on the specifications reported in UNI EN 13286-7 (Cyclic Load Triaxial Test for Unbound Mixtures) [4].

\section{Glass foam}

Glass-foam crushed stone has been used since the middle of the 1970 s as a subgrade lightweight material of pavements over soft soils. The material is $100 \%$ produced from recycled wasted glass, therefore it is sustainable and economical. The production process is based on the concept of transforming finely ground glass powder from different glass sources mixed with an activator like silica carbide into glass-foam. In the grinding process heavy metals are separated out and recycled to metal melting plants. The powder is spread on a steel belt conveyor running through high temperature ovens whereby the powder expands above 4 times, to leave the oven as a glass-foam material. When the product gets cold, after leaving the furnace, it cracks and separates into smaller units, due to the temperature shock. The normal grain size is in the range $10-60 \mathrm{~mm}$. When placed and compacted the dry density is around $150-200 \mathrm{~kg} /$ $\mathrm{m}^{3}$, depending on the compaction machinery and compaction efforts resulting more than 10 times lighter compared to traditional pavement material. Thanks to its insulating properties the material is often used as a lightweight fill material and as frost protection layer/thermal insulation in roads construction, [3-8].

\section{Investigation method}

The in situ testing program has been performed by means of the innovative Dynatest Fast Falling Weight Deflectometer (hereinafter reported as FFWD), to apply on the trial pavement sections a high number of load cycles in a short period of time[7]. The amount of cumulated permanent deformations has been monitored during the test through topographic surveys. The procedure includes the dynamic application of different load levels to measure both the stiffness stress dependency and the relationship between maximum stress and the development of permanent deformations. 


\subsection{Fast Falling Weight Deflectometer}

The investigation of the airport embankment made by glass-foam has been conducted using Dynatest FFWD, an innovative version of the traditional FWD with a new and speeder loading lifting system; where the hydraulically driven components of the conventional FWD have been replaced with an electric motor, allowing to speed up the testing process of more than 5 times. FFWD has been used to record the deflections produced in the materials, investigating different test points at different load levels [9-10]. Indeed, this new equipment allows to apply a great number of load drops over the same testing location in a short period of time, up to 2600 drops per hour [7].

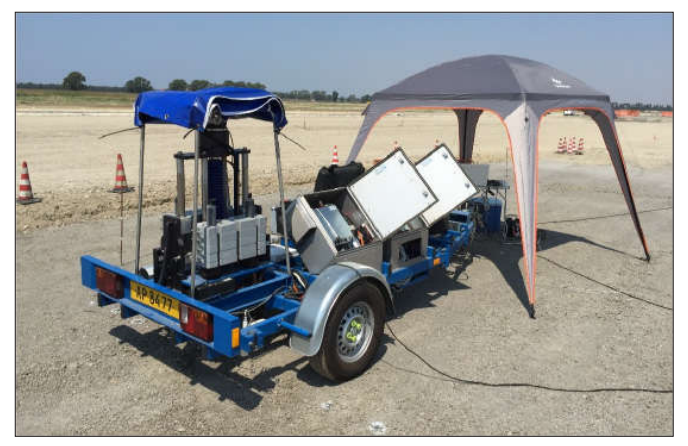

Figure 1 Fast Falling Weight Deflectometer - FFWD - on trial section

\subsection{Description of the trial section}

The APT test using Fast FWD has been undertaken at "Leonardo da Vinci" Airport, Fiumicino (Rome, Italy), where the glass-foam gravel has been used in a weight-compensation geotechnical design of the pavement structure subjected to permanent settlements. The trial sections were located on the Runway $16 \mathrm{~L} / 34 \mathrm{R}$, chainage $\mathrm{km} 0+625$ to $0+750$, characterised by the presence of a glass-foam layer of $150 \mathrm{~cm}$, used as light infill material, at a distance from the centreline between 12 and $8 \mathrm{~m}$ [6]. The positioning of the trial sections is presented in Figure 2. Two different test points have been investigated, in order to evaluate and confirm the repeatability of the data acquired during the test.

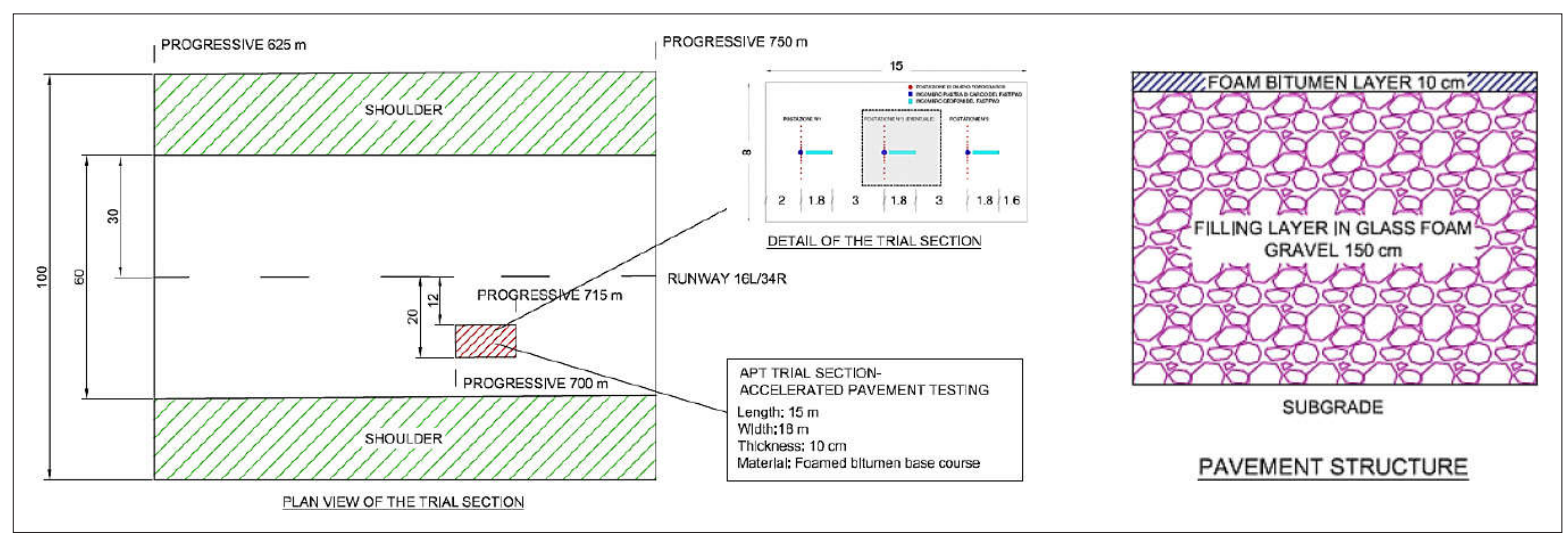

Figure 2 Trial section location and pavement structure

\subsection{Test method}

The experimental procedure has been developed starting from the standard UNI EN 13286-7 [4] regarding the evaluation of the performances of unbound mixtures. This protocol suggests 
the use of alternative test instruments and devices in order to guarantee a better representativeness of the results towards the real behaviour of the material. Moreover, the same standard prescribes to apply 10.000 repetitions for every test load level. In this research the FFWD has been set up applying three different load levels corresponding to a contact pressure under the loading plate of 450,700 and $900 \mathrm{kPa}$ (the $300 \mathrm{~mm}$ standard plate have been used). Each test point has been investigated with 10.000 load repetitions, at the previous mentioned load levels. To avoid localized failure and guarantee an adequate load spread the foam glass layer $(150 \mathrm{~cm})$ was covered with a $18-20 \mathrm{~cm}$ cement bound layer, assuming a no temperature dependency of the material. The vertical stress over the glass-foam layer was calculated in a pre-test phase using results of FFWD load application to backcalculate the pavement layers' moduli. To do that a two layer model on Dynatest ELMOD 6 software was used to run the backcalculation process using Odermark-Boussinesq MET method (Method of Equivalent Thickness). The resulting levels of stress for the real pavement structure are reported in the subsequent table where also the number of load repetitions for all the load levels are presented.

Table 1 Test levels of stress and number of load repetitions

\begin{tabular}{llll}
\hline Test points & FFWD stress applied & Resulting vertical stress on glass foam layer & Number of drops \\
\hline POINT 1 & LOW: $450 \mathrm{kPa}$ & $120 \mathrm{kPa}$ & 10.000 \\
\cline { 2 - 4 } & MEDIUM: $850 \mathrm{kPa}$ & $186 \mathrm{kPa}$ & 10.000 \\
\cline { 2 - 4 } & HIGH: $1300 \mathrm{kPa}$ & $250 \mathrm{kPa}$ & 5.000 \\
\hline POINT 2 & LOW: $450 \mathrm{kPa}$ & $120 \mathrm{kPa}$ & 10.000 \\
\cline { 2 - 4 } & MEDIUM: $850 \mathrm{kPa}$ & $186 \mathrm{kPa}$ & 10.000 \\
\cline { 2 - 4 } & HIGH: $1300 \mathrm{kPa}$ & $250 \mathrm{kPa}$ & 3.000 \\
\hline
\end{tabular}

The first load level is comparable to the nominal vertical stress limit of the glass-foam, assumed as $100 \mathrm{kPa}$ from laboratory tests carried out by the University of Pisa (data regarding this limit will be published in the near future). For the second load level is predictable that the material will guarantee suitable levels of durability. The third load level was chosen in order to produce a rapid failure of the material. For this reason, applying the third load level the test was interrupted before reaching 10.000 drops, following indication provided by the standard, UNI EN 13286-7: "When the stress paths are completed (or excessive deformations occur), remove the measuring system..." [4]. Looking at the deflections measured on the pavement applying the third load level, the test was interrupted when a rapid increase of deflections' value was recorded and/or when the failure of the tested surface was observed (Figure 3).

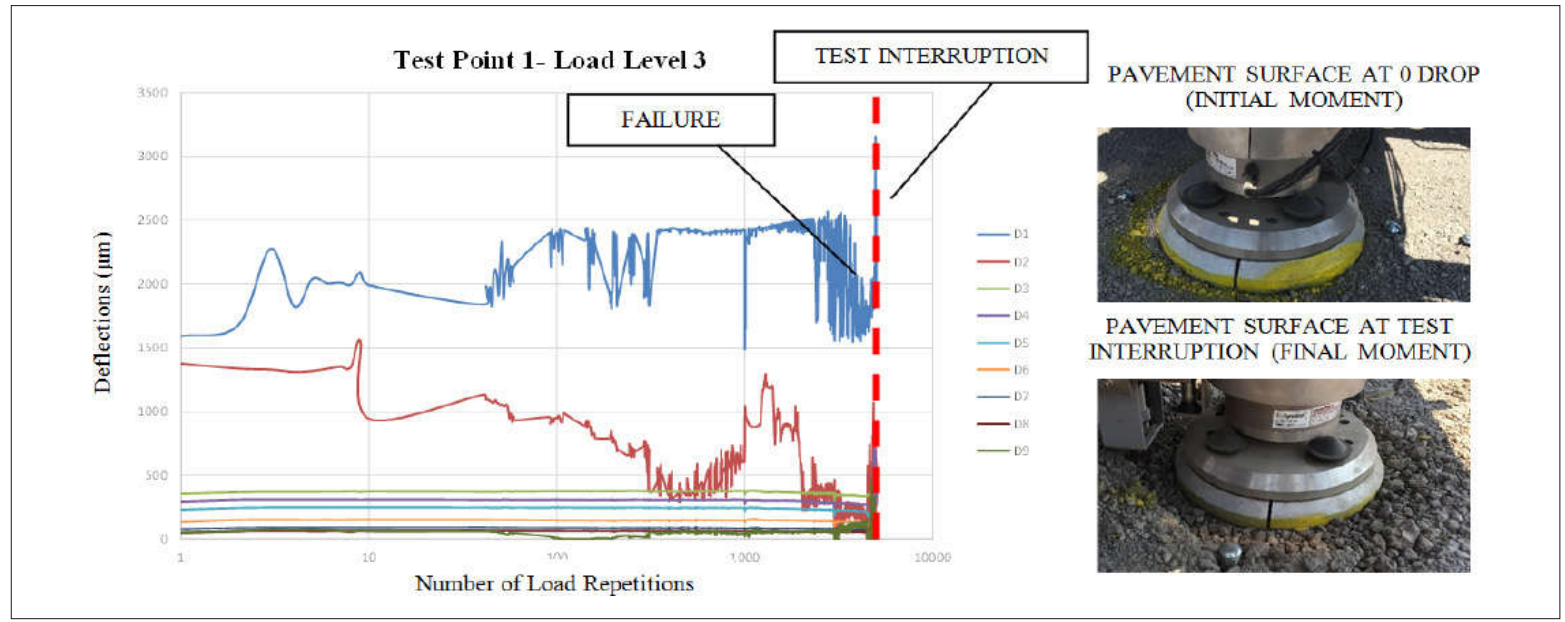

Figure 3 Method for evaluating the interruption of test progress 
The pavement settlement due to load application has been recorded through topographic surveys carried out after 0 (reference one), 1000, 3000, 6000 drops and at the end of the test (10000 load repetitions) or when failure occurred.

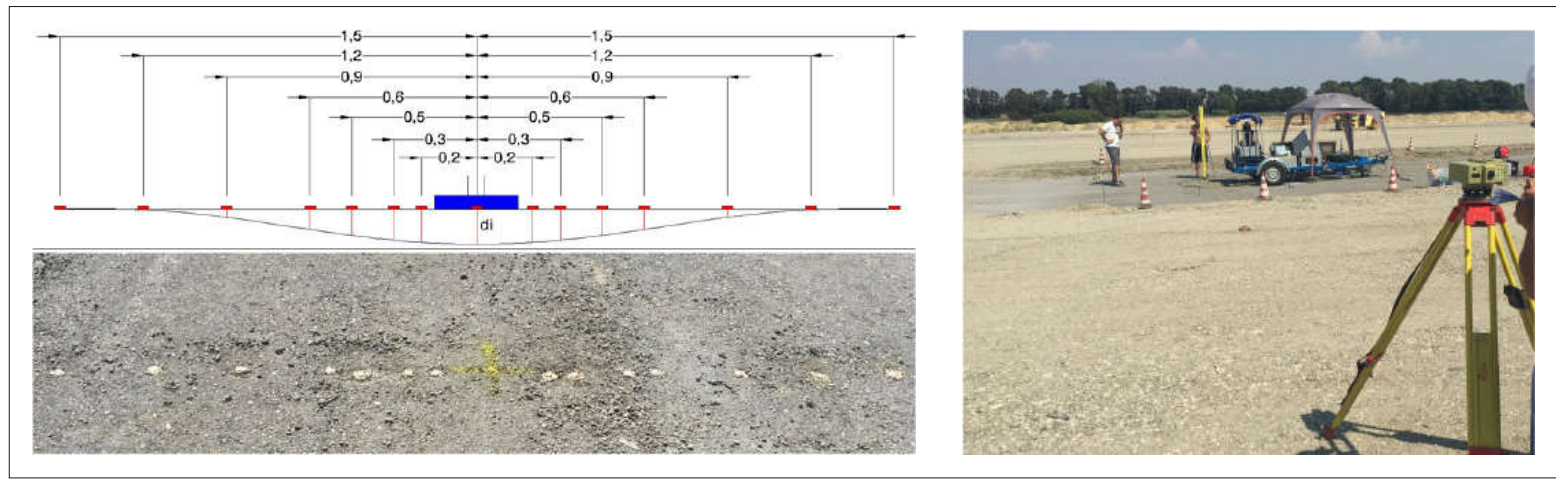

Figure 4 Scheme of the topographic survey

\section{Results and Discussion}

During the tests sessions the subsequent parameters have been recorded: i) surface deflections, recorded by FFWD geophones at different distances from the loading centre; ii) surface settlements; iii) pavement settlements defined through the topographic survey carried out during the test. The data output has been elaborated and combined in order to establish a relation between the vertical stress level and number of load repetitions. This elaboration has been realized considering some assumptions:

1) The pavement settlements measured by the topographic nail at $200 \mathrm{~mm}$ from the centre of the loading plate have been considered as the settlements of the glass-foam layer. This first assumption has been confirmed measuring the real settlement through a pavement cut at the end of the test session.

2) A settlement of $18 \mathrm{~mm}$ reached by the glass-foam layer has been considered as the failure criterion for the material. This value is the rut depth limit prescribed by the Shell method's subgrade fatigue law: "the Shell permanent deformation criterion, originally based on a terminal serviceability index of 2.5 , corresponded to a rut depth of 0.7 in $(1.8 \mathrm{~cm})$ " [9].

3) The number of load repetitions that defines the glass foam layer's settlement of $18 \mathrm{~mm}$ (failure condition), has been determined by interpolation of the value observed during the $10^{\circ} 000$ drops of each test session with different levels of load. In the figure below (Figure 5), Np values correspond to the number of load repetitions to reach the threshold defined as failure condition, for each load level, assuming that the accumulation of damage due to traffic loads generally produces an increase of vertical stress on top of the subgrade.

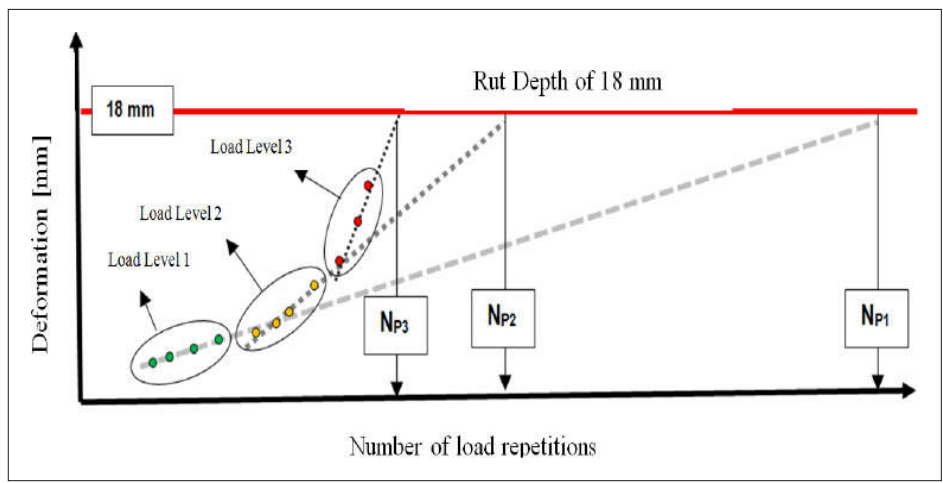

Figure 5 Scheme of the method followed to elaborate results 
The elaborations results are reported in the graphs below (Figure 6). Each settlement measurement corresponds to double point series, considering that the surveys have been conducted on two series of topographic nails, placed in symmetrical position from the loading plate.

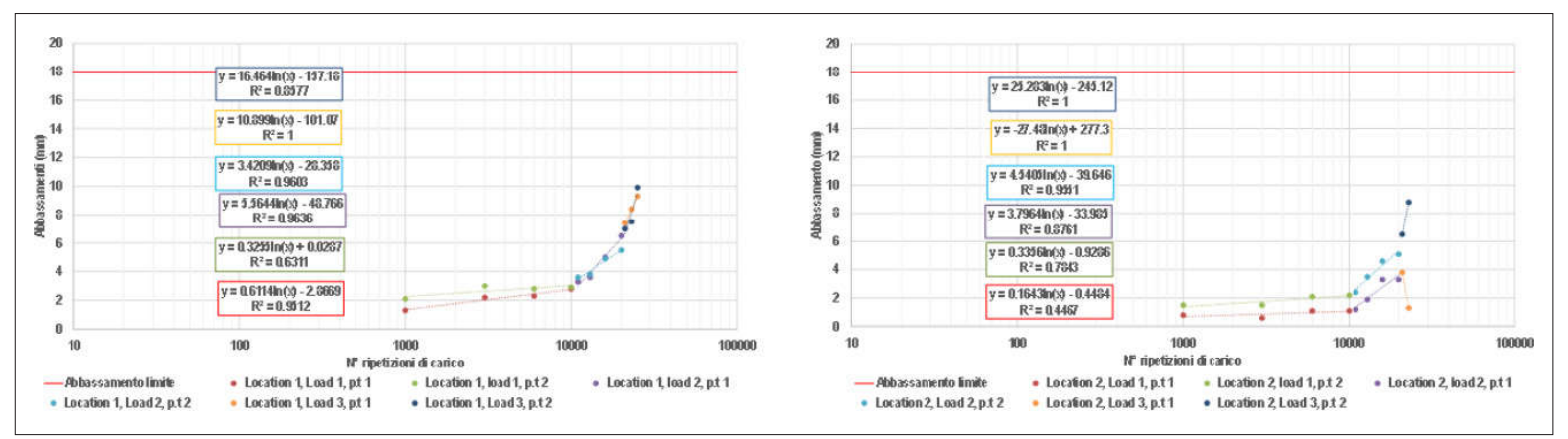

Figure 6 Development of permanent deformations recorded by the nails placed at $200 \mathrm{~mm}$ from the loading plate for a) test point 1 and b) test point 2

Applying the first load level the number of load repetitions which leads the glass-foam layer to failure results significantly high and many orders of magnitude higher than the capacity of an airport runway over a long-term horizon. The vertical stress on the glass-foam indicated by the lowest load level applied by the FFWD is about $120 \mathrm{kPa}$. This value can then be considered as the "endurance limit" of the material. This means that when the vertical stress on the glass-foam is lower than $120 \mathrm{kPa}$ there is no risk for permanent deformation to reach a critical value. The second ( $186 \mathrm{kPa})$ and third load level $(250 \mathrm{kPa})$ lead to failure in a smaller number of load repetitions. Those have been processed in order to define the trend of the admissible number of load repetitions, as function of the vertical stress on the glass foam layer. All these data have been used to develop limit curves, where the vertical stresses on the glass foam layer are related to the allowable number of load repetitions, reported in the graph below (Figure 7).

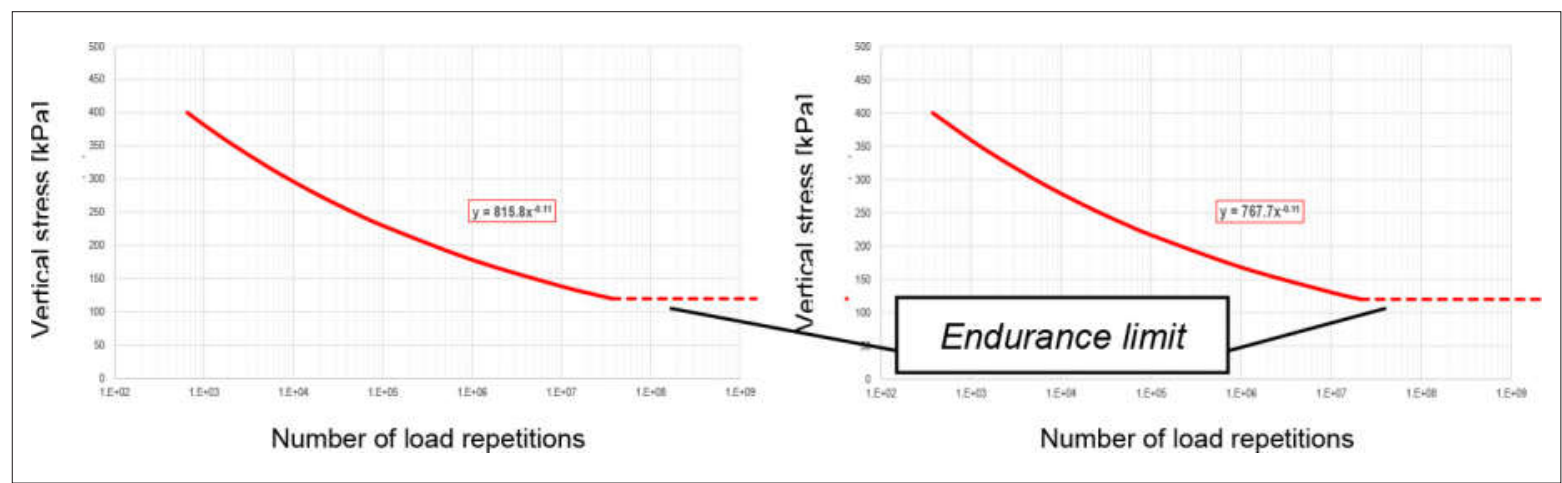

Figure 7 Vertical stress development as function of number of load repetition for a) test point 1 and b) test point 2

The limit curves, defined using the test results and considering a limit accumulation of permanent deformations on glass-foam layer of $18 \mathrm{~mm}$, could be used to identify the maximum number of passages related to a specific vertical stress on the glass-foam layer. If vertical stress on the glass foam is less than $120 \mathrm{kPa}$ the amount of permanent deformation accumulated will not be significant. The limit curves of the two studied points are extremely comparable, thus indicating an acceptable reproducibility of the experimental results of the two tests points. The defined endurance limit should be considered cautionary; a repetition of this kind of test using other load levels could probably lead to an optimization of this value. 


\section{Conclusions}

In the present study the long-term behaviour of glass-foam material has been analysed. Results are based on FFWD tests carried out on two different test points and on the surface settlements measured with topographic surveys carried out at fixed loading steps. The goal was to evaluate the amount of permanent deformations accumulated during the test and correlate it with the vertical stress applied on the glass-foam's layer. Results obtained allow to fix the subsequent points:

- The vertical stress limit on the glass foam layer of $100 \mathrm{kPa}$, fixed as the nominal maximum stress level on the material, to avoid excessive deformation can be confirmed by the results obtained in the present study;

- A vertical stress lower of $120 \mathrm{kPa}$, considering the obtained results, does not lead to accumulation of permanent deformations. This value can be considered as the endurance limit of the glass-foam;

- The correlation between the vertical stress and the number of allowable load repetitions can be used as a fatigue law for the glass-foam, to design thickness and characteristics of the upper layer. The same type of approach can be used for other types of material.

To verify these conclusions, and optimize the shape of the fatigue law other tests need to be carried out, using different load levels. The present research activity is still on-going with the aim to verify the long-term performance of some other unconventional materials.

\section{References}

[1] Marradi, A., Pinori, U., Betti, G.: The Use of Lightweight Materials in Road Embankment Construction, Procedia: Social and Behavioral Sciences, 53, pp. 1001-1010, 2012.

[2] Betti, G., Pinori, U., Marradi, A.: The use of recycled glassfoam aggregates for lightweight embankment, Sustainability, Eco-efficiency, and Conservation in Transportation Infrastructure Asset Management. pp. 245-254, doi: 10.1201/b16730-37. 2014.

[3] Emersleben, A., Meyer, M.: Sustainable pavement construction by the use of recycled glass, International Journal of Geotechnical Engineering, 8, pp. 436-440, doi: 10.1179/1939787913Y.0000000030. 2014.

[4] European Committee for Standardization, UNI EN 13286-Unbound and hydraulically bound mixtures -Part 7: Cyclic load triaxial test for unbound mixtures, Brussels, 2004.

[5] Goerge, K.P., Rahim, A.: Falling Weight Deflectometer for Estimating Subgrade Resilient Moduli, Journal of Transportation Engineering, 129, pp. 100-107, doi: 10.1061/ ASCE!0733-947X. 2003.

[6] Betti, G., Pinori, U., Marradi, A.: Glassfoam aggregates for pavements on highly compressive soil. The Fiumicino Airport case history, XV Danube-European Conference on Geotechnical Engineering (DECGE2014), pp. 71-76, Wien 9-11 September 2014.

[7] Briggs, R.C., Navarro Comes, A., Ullidtz., P.: Accelerated Pavement Testing using the Fast Falling Weight Deflectometer, Transport Research Board 95 ${ }^{\text {th }}$ Annual Meeting (No. 16-2829), Washington D.C., 2016.

[8] Aabøe, R., Øiseth, E.: Foamed glass - An alternative lightweight and insulating material, Sustainable waste management and recycling: Glass Waste, 2005.

[9] Huang, Y.H.: Pavement Analysis and Design, Second Edition, USA, 2004.

[10] Cost 336: Use of Falling Weight Deflectometer in Pavement Evaluation, 1998. 
